\title{
JQ1, a small molecule inhibitor of BRD4, suppresses cell growth and invasion in oral squamous cell carcinoma
}

\author{
LIMEI WANG ${ }^{1,2^{*}}$, XIUYIN WU ${ }^{2-4 *}$, PING HUANG $^{5}$, ZHIJUN LV $^{3}$, YUPING QI $^{6}$, \\ XIUJUAN WEI ${ }^{2,4}$, PISHAN YANG ${ }^{1,2}$ and FENGHE ZHANG ${ }^{2,4}$ \\ ${ }^{1}$ Department of Periodontology, School of Stomatology, Shandong University, Jinan, Shandong 250012; \\ ${ }^{2}$ Shandong Provincial Key Laboratory of Oral Tissue Regeneration, Jinan, Shandong 250012; \\ ${ }^{3}$ Department of Stomatology, Laiwu City People's Hospital, Laiwu, Shandong 271100; \\ ${ }^{4}$ Department of Oral and Maxillofacial Surgery, School of Stomatology, Shandong University, Jinan, Shandong 250012; \\ ${ }^{5}$ Qilu Hospital of Shandong University, Jinan, Shandong 250012; ${ }^{6}$ Department of Stomatology, Qilu Hospital, \\ and Institute of Stomatology, Shandong University, Jinan, Shandong 250012, P.R. China
}

Received March 15, 2016; Accepted April 27, 2016

DOI: 10.3892/or.2016.5037

\begin{abstract}
The present study aimed to evaluate whether bromodomain 4 (BRD4) is expressed in Cal27 cells and to assess the effect of JQ1 on cell proliferation, apoptosis, invasion and BRD4, C-Myc and Twist expression in Cal27 cells. Immunofluorescence staining was used to determine whether BRD4 was expressed in Cal27 cells. Cell viability and proliferation were evaluated using CCK-8 assay. Flow cytometry was used to determine the apoptosis and cell cycle distribution. The cell invasion was evaluated using Transwell plate. The expression levels of BRD4, C-Myc and Twist were determined by quantitative RT-PCR (qRT-PCR) and western blotting. BRD4 was highly expressed in Cal27 cells. JQ1 inhibited cell proliferation, induced cell apoptosis, induced cell cycle arrest, and inhibited cell invasion. Gene and protein expression levels of BRD4, C-Myc and Twist were downregulated in cells treated with JQ1. JQ1 inhibited Cal27 cell growth and invasion, and downregulated expression of several oncogenes. JQ1 may be a new drug for oral squamous cell carcinoma treatment.
\end{abstract}

Correspondence to: Dr Fenghe Zhang, Department of Oral and Maxillofacial Surgery, School of Stomatology, Shandong University, 44-1 Wenhua Road West, Jinan, Shandong 250012, P.R. China

E-mail: zfengh@sdu.edu.cn

Dr Pishan Yang, Department of Periodontology, School of Stomatology, Shandong University, 44-1 Wenhua Road West, Jinan, Shandong 250012, P.R. China

E-mail: yangps@sdu.edu.cn

${ }^{*}$ Contributed equally

Key words: oral squamous cell carcinoma, BRD4, JQ1, C-Myc, Twist, invasion

\section{Introduction}

Oral squamous cell carcinoma (OSCC) is a lethal intraoral malignancy associated with high morbidity and mortality; the 5 -year survival rate is less than 50\% (1). There are no effective means to cure this disease. In order to develop successfully molecular-targeted therapies against this tumor, the first and most important procedure is to reveal its pathogenesis and identify critical oncogenes.

As a member of the bromodomain and extraterminal (BET) family, bromodomain 4 (BRD4) plays a critical role in gene regulation by facilitating the recruitment of the active form of the positive transcription elongation factor $\mathrm{b}$ (P-TEFb) (2). Abnormal activation of the BRD4 gene is associated with the tumorigenesis of many human malignancies. Previous studies have reported that BRD4 is significantly overexpressed in a range of malignant tumors including bladder cancer, multiple myeloma, non-small cell lung cancer, leukemia and hepatocellular carcinoma (3-7). BRD4 inhibition by small molecule inhibitors and siRNA has been demonstrated to be a therapeutic strategy in many malignant tumors $(4,8)$.

Twist is a member of the basic helix-loop-helix protein family and a key member of epithelial-to-mesenchymal transition (EMT)-activating transcriptional factors (9-12). The roles of Twist in tumor progression have been well investigated. It has been reported that Twist is a potential oncogene that inhibits apoptosis, and increases migration and invasion in several types of tumors (12-14). Shi et al demonstrated that BRD4 interacts with di-acetylated Twist which is critical for the tumorigenicity of breast cancer, and they proposed that the Twist-BRD4 complex may be a potential drug target for basal-like breast cancer $(9,15)$.

The C-Myc proto-oncogene belongs to the MYC family, which also includes MYCN (N-Myc) and MYCL (L-Myc) (16). As a critical transcription regulator, C-Myc plays a vital role in many physiological processes of regulation, such as cell cycle control, protein synthesis, cell adhesion and apoptosis (17). Evidence shows that nearly half of human tumors, including 
leukemia and many solid tumors are associated with the overexpression of the C-Myc gene (18-21). C-Myc contributes to the pathogenesis of a majority of human malignant tumors by promoting multiple processes, including uncontrolled cell proliferation, cell growth and genomic instability (16). It was found that $\mathrm{C}$-Myc regulates promoter-proximal pause of Pol II through the recruitment of P-TEFb, which indicates that BRD4 inhibition is a therapeutic strategy in human tumors to target C-Myc (4,22).

The above-mentioned studies demonstrate that BRD4, C-Myc and Twist all play important roles in tumor development and are the key treatment targets for a range of human malignant tumors.

JQ1 is a BET-BRD inhibitor that has high binding affinity for BRD4, and has been shown to be profoundly efficacious against many malignant tumors, including hepatocellular carcinoma, lung, gastric and colon cancer (4,7,23-26). Previous studies have reported that JQ1 treatment significantly downregulated C-Myc expression in several tumors including Kras-mutant non-small cell lung cancer and medulloblastoma cells, and T cell acute lymphoblastic leukemia (24,27,28). JQ1 also disrupts the interaction of BRD4 with Twist leading to suppression of breast cancer (15). All in all, JQ1, as a small molecule inhibitor of BRD4, can suppress tumorigenesis in several human malignant tumors. While C-Myc and Twist have been identified as important oncogenes in $\operatorname{OSCC}(29,30)$, the effect of JQ1 on these gene signals of OSCC has not been well investigated. Moreover, the genetic status of BRD4 in OSCC is not yet defined.

In the present study, we hypothesized that the BRD4 inhibitor, JQ1, may inhibit the development and metastasis of OSCC via the suppression of C-Myc and Twist. To test our hypothesis, we investigated the effects of JQ1 at different concentrations on the proliferation, apoptosis and invasion of Cal27 cells, as well as on protein expression of BRD4, C-Myc and Twist.

\section{Materials and methods}

Cell culture. Cal27 cells (provided by Shanghai Ninth People's Hospital) were cultured in high-glucose Dulbecco's modified Eagle's medium (DMEM) (HyClone, Logan, UT, USA), supplemented with $10 \%$ fetal bovine serum (FBS; Gibco, Grand Island, NY, USA), $100 \mathrm{U} / \mathrm{ml}$ penicillin and $100 \mu \mathrm{g} / \mathrm{ml}$ streptomycin (Invitrogen, Camarillo, CA, USA) with 5\% $\mathrm{CO}_{2}$ at $37^{\circ} \mathrm{C}$. In the present study, cells were maintained in a culture medium supplemented with JQ1 (Selleck Chemicals, Houston, TX, USA) at concentrations of $0.1,0.5$ and $1 \mu \mathrm{M}$. Dimethyl sulfoxide (DMSO) was added in the control group.

Immunocytochemical analysis. Cal27 cells were plated on coverslips at $2.5 \times 10^{4}$ cells/well into 24 -well plates in $300 \mu \mathrm{l}$ of high-glucose DMEM in the presence of $10 \%$ FBS. After $24 \mathrm{~h}$, the cells were fixed in $4 \%(\mathrm{v} / \mathrm{v})$ paraformaldehyde for $15 \mathrm{~min}$, permeabilized with $0.1 \%$ Triton $\mathrm{X}-100$ for $3 \mathrm{~min}$, and blocked with $10 \%$ donkey serum $(2 \mathrm{~h})$. The cells were then incubated with 1:200 primary rabbit anti-human BRD4 monoclonal (catalogue no. ab128874), mouse anti-human C-Myc monoclonal (catalogue no. ab32) and rabbit antihuman Twist polyclonal antibodies (catalogue no. ab50581) (all from Abcam, Cambridge, MA, USA) overnight at $4^{\circ} \mathrm{C}$. After washing, the cells were incubated with 1:200 goat antirabbit (catalogue no. SP-9000) and goat anti-mouse (catalogue no. SP-9002) (both from ZSGB-BIO OriGene, Beijing, China) secondary antibodies. 4',6-Diamidino-2-phenylindole (DAPI) was used as the nuclear counterstain. Images were collected by fluorescence microscopy.

Cell proliferation assay. The proliferation of cells was measured using Cell Counting Kit-8 (CCK-8; Dojindo, Tokyo, Japan). Cal27 cells were seeded in 96-well plates at a density of 2,000 cells/well and cultured with high-glucose DMEM containing $10 \%$ FBS. After $24 \mathrm{~h}$, the groups were switched to high-glucose DMEM containing 2\% FBS and different concentrations of JQ1. After 1-5 days, $10 \mu \mathrm{l}$ of CCK-8 solution was added to each well, and the plates were incubated for $2.5 \mathrm{~h}$ at $37^{\circ} \mathrm{C}$. The optical density (OD) levels were measured by a microplate reader scanning at $450 \mathrm{~nm}$ according to the manufacturer's instructions.

Annexin V/PI assays for apoptosis. Cal27 cells were seeded into 6-well plates at a density of $1 \times 10^{5}$ cells/well, and then maintained with the aforementioned medium, which was supplemented with JQ1 at the concentration of $0.5 \mu \mathrm{M}$. After $48 \mathrm{~h}$, the apoptosis of cells was detected by flow cytometry (FCM) with an Annexin V-FITC/propidium iodide (PI) apoptosis detection kit (eBioscience, Vienna, Austria) according to the manufacturer's instructions. Briefly, Cal27 cells were washed once in a phosphate-buffered saline (PBS) and once in a $1 \mathrm{X}$ binding buffer. The cells were then resuspended in a $1 \mathrm{X}$ binding buffer, and $5 \mu \mathrm{l}$ of fluorochrome-conjugated Annexin V was added to each one. After incubation for $10 \mathrm{~min}$ at room temperature, the cells were washed in a $1 \mathrm{X}$ binding buffer. After adding $5 \mu \mathrm{l}$ of PI staining solution, the apoptotic cells were determined using a flow cytometer (FACSCalibur; BD Biosciences, San Jose, CA, USA). Both early and late apoptotic cells were included in cell death determinations.

Cell cycle analysis. Cell cycle analysis was performed to evaluate the influence of JQ1 on the Cal27 cell cycle using a Cell Cycle and Apoptosis Analysis kit (Beyotime, Shanghai, China). After $24 \mathrm{~h}$ of treatment with JQ1 at different concentrations, the cells were washed once with PBS, and then resuspended in $1 \mathrm{ml}$ of ice-cold $70 \%$ ethanol and fixed for $12 \mathrm{~h}$ at $4^{\circ} \mathrm{C}$. Then, the cells were washed with PBS and stained with $500 \mu \mathrm{l}$ staining solution (PI) for $30 \mathrm{~min}$ at $37^{\circ} \mathrm{C}$. Cell cycle data were obtained using a flow cytometer. The percentages of cells at the G1, G2 and S phases were analyzed.

In vitro invasion assay. An in vitro cell invasion assay was performed to evaluate the influence of JQ1 on the metastasis of Cal27 cells. A Corning ${ }^{\circledR}$ Matrigel ${ }^{\circledR}$ Basement Membrane Matrix (Becton-Dickinson and Co., Mountain View, CA, USA), which was used to mimic the extracellular matrices underlying the cells in vivo, was plated on the upper compartment of a 24-well Transwell plate ( $8 \mu \mathrm{m}$; Costar, Cambridge, MA, USA). Cal27 cells $\left(1 \times 10^{5}\right)$ in high-glucose DMEM supplemented without FBS and JQ1 at different concentrations were plated on the matrix. As a chemoattractant, the lower compartment contained high-glucose DMEM supplemented with $10 \%$ 
FBS. After $48 \mathrm{~h}$ of incubation, cells on the upper surface of the filter were removed gently with a cotton swab, while cells on the lower surface were washed with PBS, fixed in $4 \%$ paraformaldehyde for $30 \mathrm{~min}$ at room temperature, and were then stained with $0.1 \%$ crystal violet. The number of cells on the lower surface was counted under a light microscope in five randomly selected fields, and the mean number of cells was calculated per field.

Quantitative RT-PCR ( $q R T-P C R$ ) assay. The Cal27 cells were seeded into 6-well plates at a density of $1 \times 10^{5}$ cells/well. After $24 \mathrm{~h}$, the groups were switched to high-glucose DMEM containing $10 \%$ FBS and JQ1 at different concentrations. Total RNA was extracted using a TRIzol ${ }^{\circledR}$ reagent (Takara Bio, Dalian, Japan) after 24 and $48 \mathrm{~h}$ according to the manufacturer's protocol, and reverse-transcribed into cDNA using the Biometra Reverse Transcription system (Biometra) at $42^{\circ} \mathrm{C}$ for $2 \mathrm{~min}$, and $4^{\circ} \mathrm{C}$ for $30 \mathrm{~min}$; the second step at $37^{\circ} \mathrm{C}$ for $15 \mathrm{~min}$ at $85^{\circ} \mathrm{C}$ for $5 \mathrm{sec}$, and $4^{\circ} \mathrm{C}$ for $30 \mathrm{~min}$ with the reverse transcriptase kit (Takara Bio). qRT-PCR was run in $20 \mu \mathrm{l}$ of the reaction system containing $10 \mu \mathrm{l}$ of $2 \mathrm{X}$ PCR Master Mix, $0.4 \mu \mathrm{l}$ of each primer, $2 \mu \mathrm{l}$ of cDNA and $7.2 \mu 1$ of nuclease-free water on a LightCycler Roche 480 with SYBR ${ }^{\circledR}$ Primix Ex $\mathrm{Taq}^{\mathrm{TM}}$ kit (Takara Bio) under the following conditions: at $95^{\circ} \mathrm{C}$ for $30 \mathrm{sec}$; 45 cycles at $95^{\circ} \mathrm{C}$ for $5 \mathrm{sec}$, at $60^{\circ} \mathrm{C}$ for $35 \mathrm{sec}$ and at $72^{\circ} \mathrm{C}$ for $1 \mathrm{~min}$; finally at $40^{\circ} \mathrm{C}$ for $30 \mathrm{sec}$, while GAPDH served as a reference gene. Relative quantity of mRNA expression was calculated using the $2^{-\Delta \Delta \mathrm{Ct}}$ method. All experiments were repeated in triplicate. The sequences of the primers for amplification of human BRD4, C-Myc, Twist and GAPDH were as follows: BRD4, 5'-ACCTCCAACCCTAACAAGCC-3' and 5'-TTTCCATAGTGTCTTGAGCACC-3'; C-Myc, 5'-GGCT CCTGGCAAAAGGTCA-3' and 5'-CTGCGTAGTTGTGC TGATGT-3'; Twist, 5'-GTCCGCAGTCTTACGAGGAG-3' and 5'-GCTTGAGGGTCTGAATCTTGCT-3'; GAPDH, 5'-GCAC CGTCAAGGCTGAGAAC-3' and 5'-TGGTGAAGACGCCA GTGGA-3'.

Western blot analysis. The Cal27 cells were seeded in 6-well plates at a density of $1 \times 10^{5}$ cells/well, and were then maintained in high-glucose DMEM with JQ1 at different concentrations. After 24 and $48 \mathrm{~h}$, proteins were extracted from the cells using RIPA containing $1 \%$ phenylmethylsulfonyl fluoride (PMSF) (both from Beyotime) for $30 \mathrm{~min}$. The protein concentration was determined using the bicinchoninic acid (BCA) assay. An amount of $20 \mu \mathrm{g}$ of total protein was run on a $10 \%$ SDS-PAGE gel (Beyotime) and electrotransferred to polyvinylidene fluoride (PVDF) membrane (Invitrogen) for $1 \mathrm{~h}$ at $100 \mathrm{~V}$ in transfer buffer. The PVDF membrane were then blocked with $5 \%$ non-fat milk for $1 \mathrm{~h}$ at room temperature, and probed with 1:1,000 primary rabbit anti-human BRD4 monoclonal (catalogue no. ab128874), mouse anti-human C-Myc monoclonal (catalogue no. ab32), rabbit anti-human Twist polyclonal antibodies (catalogue no. ab50581) (all from Abcam), and rabbit anti-human cleaved-caspase 3 polyclonal antibody (catalogue no. 9661S; CST, Danvers, MA, USA) overnight at $4^{\circ} \mathrm{C}$ on a gentle shaker. Following washing with TBST $(20 \mathrm{mmol} / 1$ Tris- $\mathrm{HCl}, 150 \mathrm{mmol} / \mathrm{l} \mathrm{NaCl}$ and $0.05 \%$ Tween-20; pH 7.4) three times, for 10 min each time, the membrane was incubated in 1:5,000 HRP-labeled horse anti-mouse $\operatorname{IgG}$ (catalogue no. 7076S) or goat anti-rabbit IgG (catalogue no. 7074S) (both from CST). The proteins were visualized using the Chemiluminescent HRP Substrate (Millipore, Billerica, MA, USA).

Statistical analysis. All data were analyzed and expressed as the mean \pm SEM from at least three replicates for each experiment. SPSS 16.0 software was used for data analysis. The significance of differences between the experimental groups and the control group was analyzed using one-way ANOVA. P-values $<0.05$ were considered to indicate statistically significant results.

\section{Results}

BRD4, C-Myc and Twist are highly expressed in the Cal27 cell line. We first explored whether these proteins were expressed in the Cal27 cell line. Immunofluorescence (IFC) staining showed that BRD4, C-Myc and Twist were highly expressed in the Cal27 cells. BRD4 was mainly located in the nucleus and C-Myc was expressed in the cytoplasm. Twist was expressed mainly in the nucleus and slightly in the cytoplasm (Fig. 1).

$J Q 1$ reduces Cal27 cell proliferation. To evaluate the influence of JQ1 on the proliferation of Cal27 cells, CCK-8 assays were performed by treating cells with various concentrations of JQ1 for five days. The results showed that, compared with the control group, cell proliferation was significantly decreased following treatment with JQ1 throughout the duration of the experiment, and the inhibitory effect was dose-dependent $(\mathrm{P}<0.05)$ (Fig. 2).

JQ1 induces cell cycle arrest and apoptosis in Cal27 cells. To investigate the cellular mechanism underlying the antiproliferative effects of JQ1 in Cal27 cells, we analyzed cell cycle distribution using FCM. JQ1 treatment at the concentrations of $0.1,0.5$ and $1 \mu \mathrm{M}$ for $24 \mathrm{~h}$ led to a decreased percentage of Cal27 cells in the $\mathrm{S}$ phase, and an increase in the percentage of cells in the G1 phase $(\mathrm{P}<0.05)$ (Fig. 3A and B). Next, we evaluated apoptotic signaling pathways with western blot assays. The results showed that a 24-h treatment with JQ1 at the concentration of $0.1 \mu \mathrm{M}$ had no effect on the protein expression of cleaved caspase- 3 in the Cal 27 cells when compared with the control group. Nevertheless, the protein expression of cleaved caspase-3 was significantly upregulated after a 24-h treatment with JQ1 at the concentrations of 0.5 and $1 \mu \mathrm{M}$ $(\mathrm{P}<0.05)$ (Fig. 3C). Then, we assessed apoptosis using FCM. JQ1 treatment at the concentration of $0.5 \mu \mathrm{M}$ for $48 \mathrm{~h}$ led to a significantly increased percentage of early stage apoptosis in Cal27 cells when compared with the control group $(\mathrm{P}<0.05)$ (Fig. 3D). JQ1 also induced Cal27 cells to shrink, round and float, which are morphological changes characteristic of apoptosis.

JQ1 reduces Cal27 cell invasion. Metastasis is a significant pathological process in cancer. Consequently, an invasion assay was performed using a Transwell to verify whether JQ1 attenuates the metastatic capability of Cal27 cells. Following treatment for $48 \mathrm{~h}$ with JQ1 at concentrations of $0.1,0.5$ and $1 \mu \mathrm{M}$, respectively, the cell counts on the lower surface for 

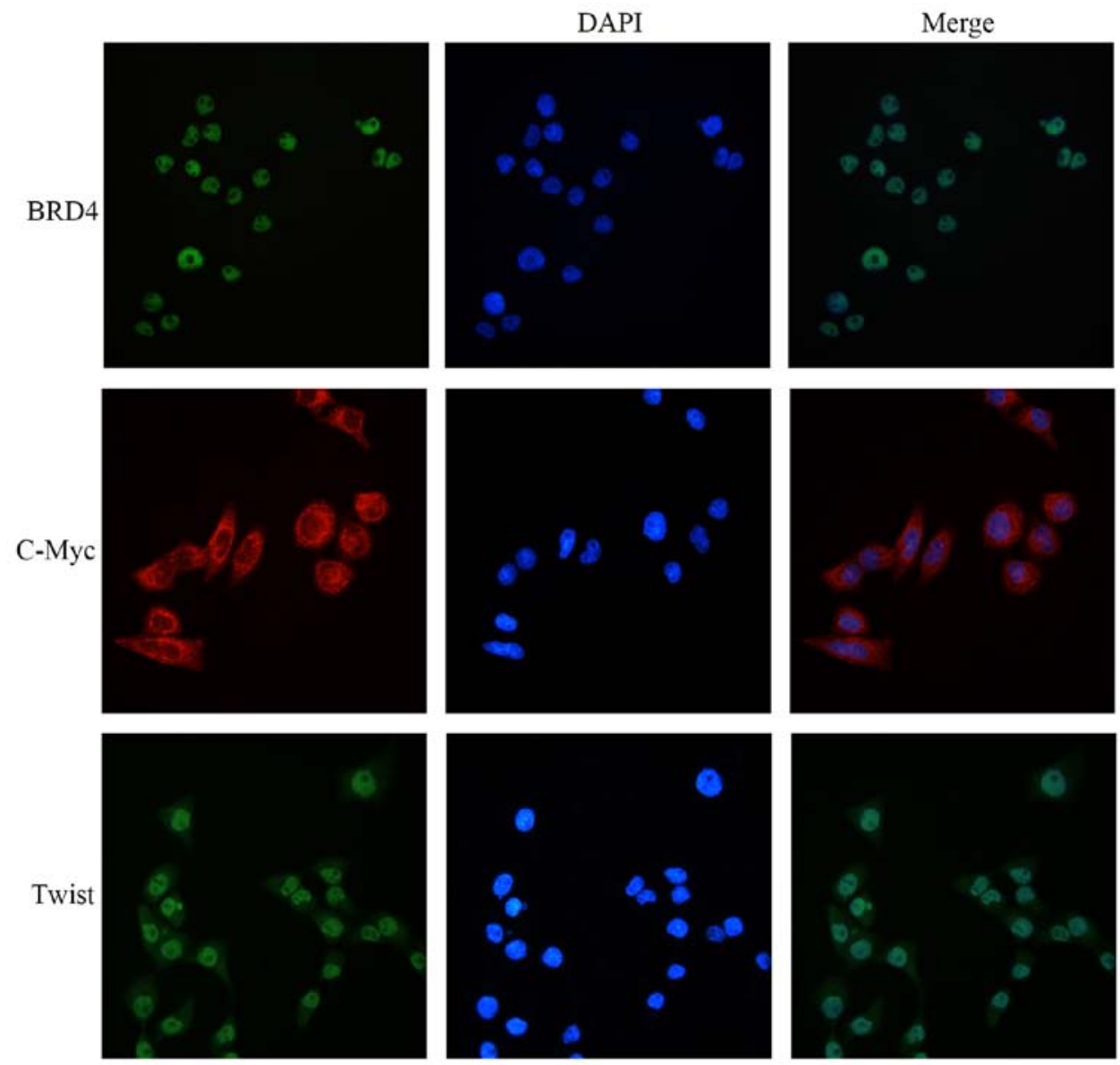

Figure 1. BRD4, C-Myc and Twist are highly expressed in the Cal27 cells. Immunofluorescent staining showed that BRD4, C-Myc and Twist were highly expressed in the Cal27 cells. BRD4 was located in the nucleus. C-Myc was expressed in the cytoplasm. Twist was expressed mainly in the nucleus and slightly in the cytoplasm.

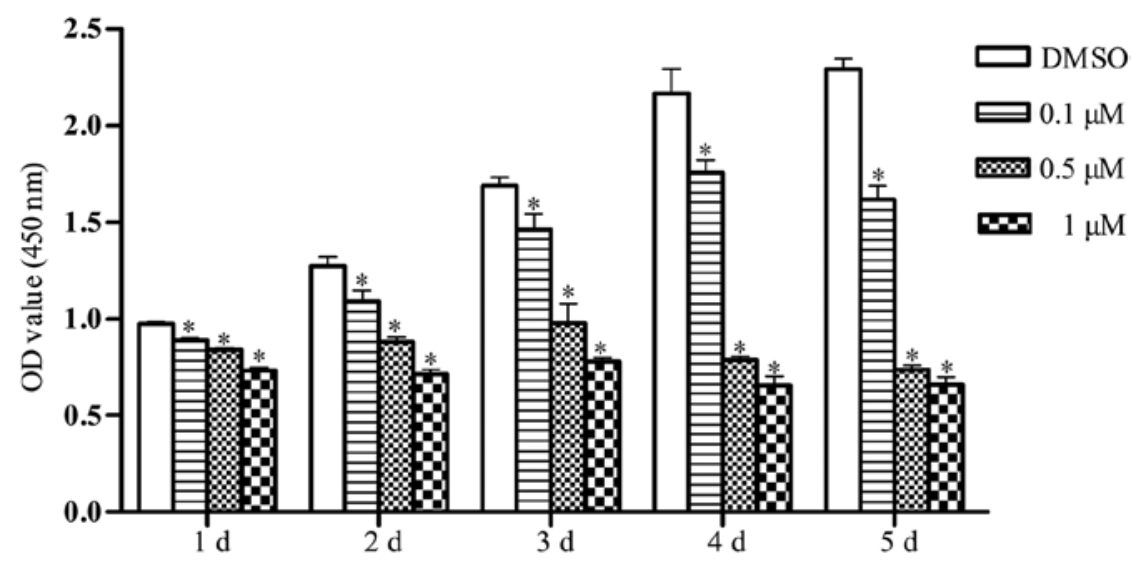

Figure 2. JQ1 reduces Cal27 cell proliferation. Proliferation of Ca127 cells after JQ1 treatment. CCK-8 assay revealed that JQ1 reduced Cal27 cell proliferation compared with that noted in the control group throughout the duration ( 5 days) of the experiment; ${ }^{*} \mathrm{P}<0.05$ vs. control (the DMSO group).

the Cal27 cells were significantly reduced when compared with the control group, and the decrease was dose-dependent $(\mathrm{P}<0.05)$ (Fig. 4A-E). JQ1 reduced cell proliferation and induced apoptosis, which may have influenced the cell counts, but there was no evidence that the invasion was blocked by the cellular debris, and the difference in cell counts was statistically significant compared to the control. Therefore, the results revealed that BRD4 inhibition via JQ1 suppressed Cal27 cell invasion, and BRD4 is a key player in this process.

JQ1 represses BRD4, C-Myc, and Twist expression in Cal27 cells. We evaluated whether JQ1 treatment suppressed expression of BRD4, C-Myc and Twist in the Cal27 cells using qRT-PCR and western blot assays. The results of 

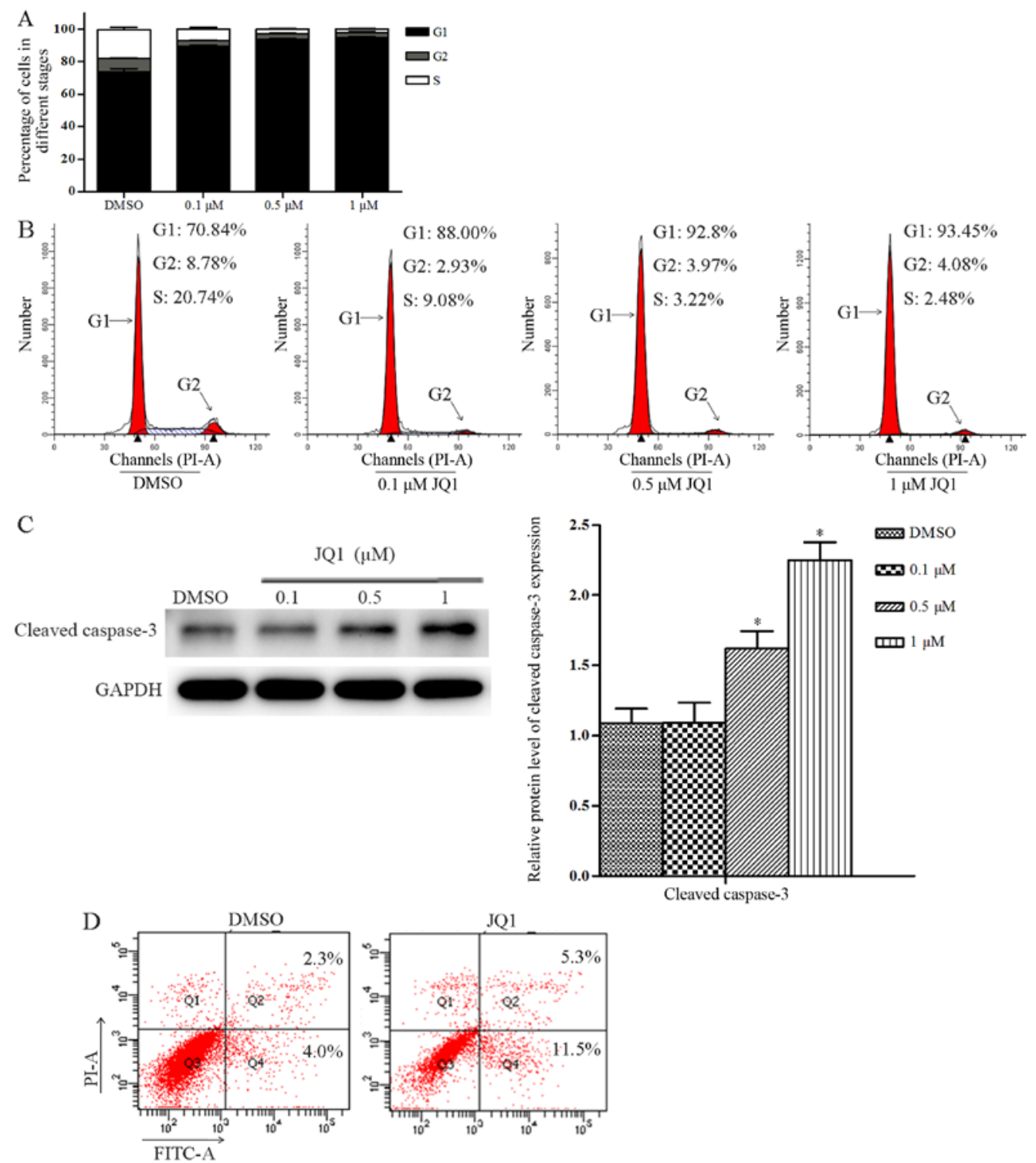

Figure 3. JQ1 induces cell cycle arrest and apoptosis in Cal27 cells. (A) The percentage of cells in each phase of the cell cycle is shown for the Ca127 cell line treated with $0.1,0.5$ and $1 \mu \mathrm{M}$ JQ1. (B) Representative plots of the cell cycle phases are shown for the Cal27 cell line treated with $0.1,0.5$ and $1 \mu \mathrm{M}$ JQ1 (C) Cal27 cells were treated with JQ1 for $24 \mathrm{~h}$ and whole cell lysates were tested by western blot assays for the expression of cleaved-caspase-3. GAPDH was used as a loading control. (D) Apoptosis of Cal27 cells treated with JQ1 at 0 and $0.5 \mu \mathrm{M} \mathrm{JQ1;}{ }^{*} \mathrm{P}<0.05$ vs. control (the DMSO group).
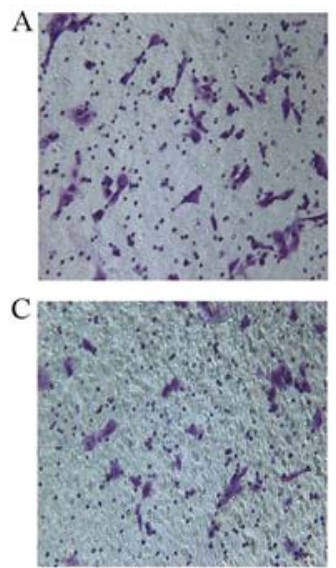
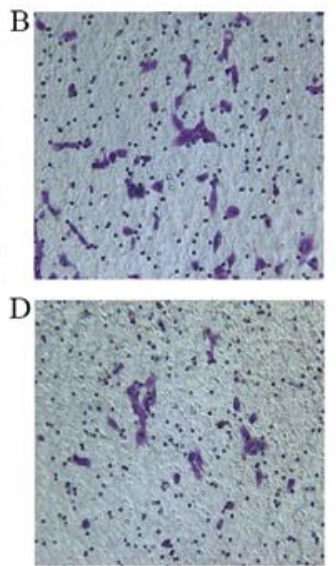

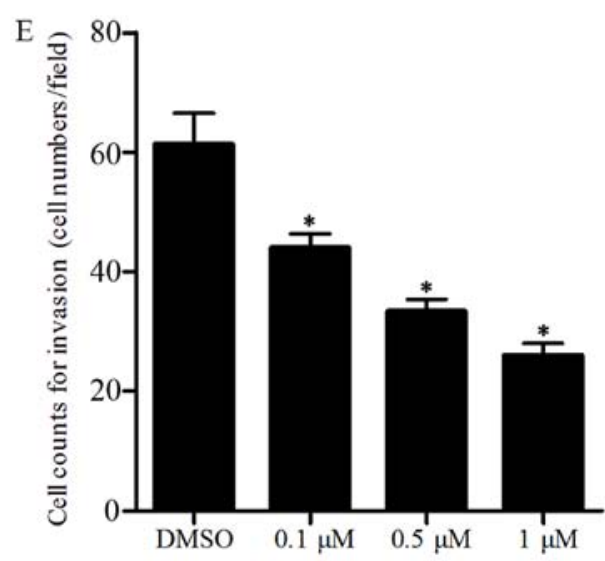

Figure 4. JQ1 reduces Cal27 cell invasion. Cal27 cell invasion was inhibited by JQ1. The cell counts of Cal27 cells on the lower surface were reduced when compared with the control group, and the inhibitory effect was dose-dependent. (A) Cal27 cells treated with DMSO. (B) Cal27 cells treated with $0.1 \mu \mathrm{M}$ JQ1. (C) Cal27 cells treated with $0.5 \mu \mathrm{M}$ JQ1. (D) Cal27 cells treated with $1 \mu \mathrm{M} \mathrm{JQ1}$. (E) Quantitative analysis of cells on the lower surface; ${ }^{*} \mathrm{P}<0.05$ vs. control (the DMSO group). 

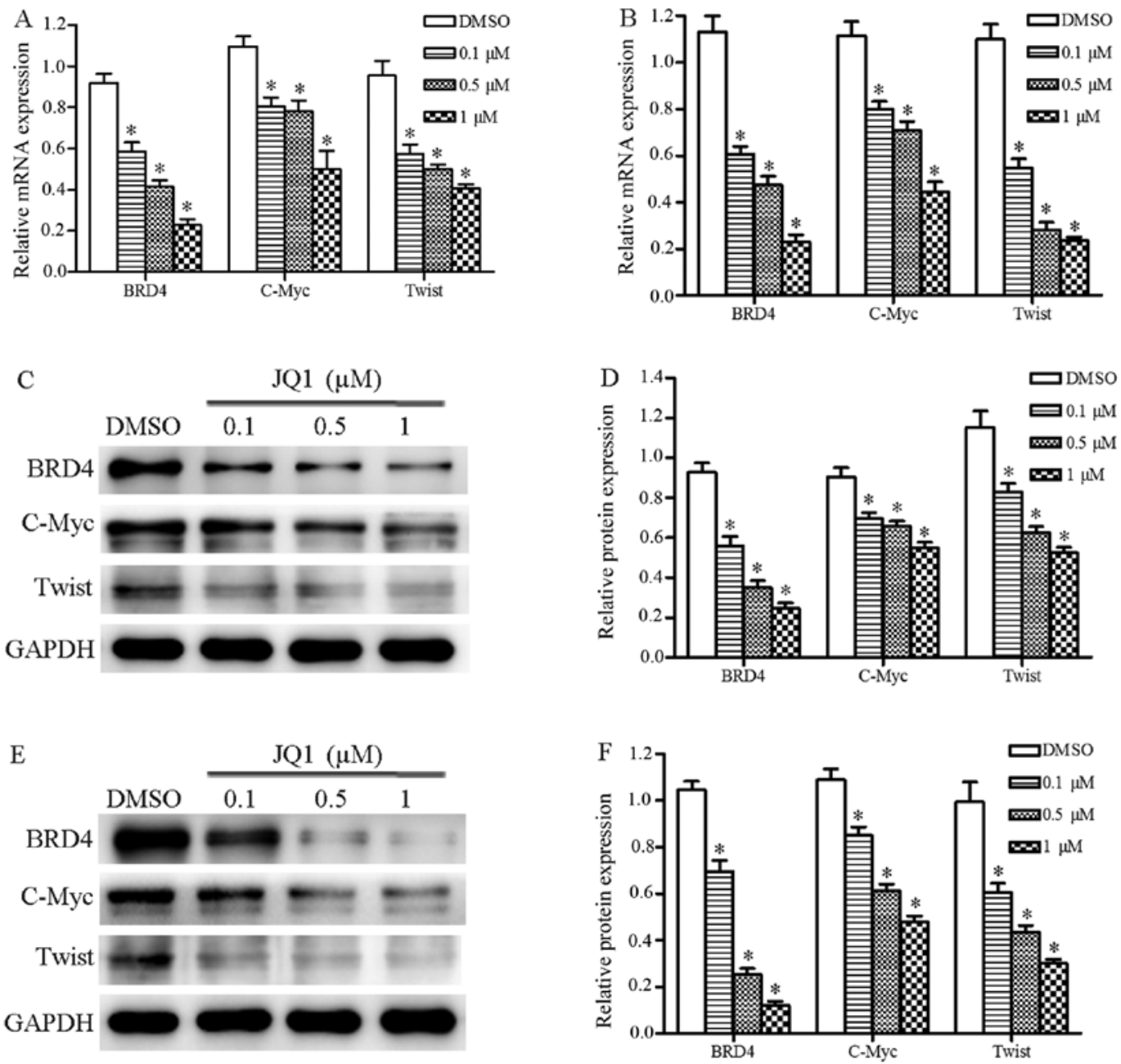

Figure 5. JQ1 represses mRNA and protein expression of C-Myc, BRD4 and Twist in the Cal27 cells. The mRNA and protein expression of BRD4, C-Myc and Twist were downregulated by JQ1 at the concentrations of $0.1,0.5$ and $1 \mu \mathrm{M}$. The expression level of each mRNA and protein was normalized against GAPDH. (A) Relative mRNA expression levels of BRD4, C-Myc and Twist in Cal27 cells after $24 \mathrm{~h}$. (B) Relative mRNA expression levels of BRD4, C-Myc and Twist in the Cal27 cells after 48 h. (C) Protein expression levels of BRD4, C-Myc and Twist in the Cal27 cells after $24 \mathrm{~h}$. (D) Quantitative analysis of protein expression levels of BRD4, C-Myc and Twist in cells after 24 h. (E) Protein expression levels of BRD4, C-Myc and Twist in the Cal27 cells after 48 h. (F) Quantitative analysis of protein expression levels of BRD4, C-Myc and Twist in the cells after $48 \mathrm{~h}$; " $\mathrm{P}<0.05$ vs. control (the DMSO group).

qRT-PCR revealed that JQ1 inhibited the mRNA expression of BRD4, C-Myc and Twistin Cal27 cells after 24 and $48 \mathrm{~h}$ $(\mathrm{P}<0.05)$ (Fig. 5A and B). Western blot assays consistently demonstrated that the protein expression levels of BRD4, $\mathrm{C}-\mathrm{Myc}$ and Twist were repressed in cells treated with JQ1 after 24 and $48 \mathrm{~h}(\mathrm{P}<0.05)$ (Fig. 5C-F). These data demonstrated that JQ1 significantly suppressed expression levels of several oncogenes and may be used in OSCC treatment.

\section{Discussion}

BRD4 deregulation is important in the pathogenesis of multiple human malignant tumors $(5,31)$, and BRD4 has been proven to be a therapeutic target for several malignant tumors (7,32-34). Studies have demonstrated that inhibition of BRD4 by JQ1 suppresses the growth of many tumors such as thyroid cancer and hepatocellular carcinoma by decreasing tumor cell viability, inducing cell apoptosis and repressing expression of C-Myc $(7,35)$. However, the role of BRD4 in OSCC and the effect of BRD4 inhibitor JQ1 on oral squamous cell carcinoma (OSCC) have not been well investigated. In the present study, we evaluated the expression of BRD4 in OSCC cell line, Cal27, and the effect of JQ1 on Cal27 cell proliferation, apoptosis, invasion and expression of oncogenes to analyze whether BRD4 could be a target for the treatment of OSCC.

JQ1 is the first generation of BET-specific inhibitors. It can displace BRD4 from chromatin by competitively binding to the acetyl-lysine recognition pocket $(23,36)$ resulting in downregulated expression of a range of oncogenes including C-Myc, Twist and many other oncogenes. To analyze the effect of JQ1 on OSCC, we first investigated whether BRD4, C-Myc and Twist were expressed in Cal27 cells by IFC staining. The result showed that BRD4, C-Myc and Twist were highly expressed in Cal27 cells. BRD4 was mainly located in the nucleus, and C-Myc was expressed in the cytoplasm, while Twist was detected both in the nucleus and in the cytoplasm. These data demonstrated that BRD4 along with well known $\mathrm{C}-\mathrm{Myc}$ and Twist are pivotal genes in OSCC development.

Considering the important role of BRD4 in other malignant tumor cells, we proposed that BRD4 could be a key player in Cal27 cells and that BRD4 inhibitor JQ1 may suppress Cal27 
cell growth. In order to confirm our hypothesis, we investigated the effect of JQ1 on Cal27 cell growth and invasion and found that JQ1 treatment at different concentrations effectively decreased cell proliferation and inhibited cell invasion. To investigate the cellular mechanism underlying the antiproliferative effects of JQ1 in Cal27 cells, cell cycle distribution and cell apoptosis after JQ1 treatment were analyzed. The results found that JQ1 induced early stage apoptosis, arrested cell cycle progression at the G1 phase and upregulated cleaved caspase- 3 expression at low concentration ranges in the Cal27 cells. These data suggest that JQ1 suppresses OSCC cell survival and promotes cell apoptosis, which are in agreement with the effect of JQ1 on many other malignant cells $(7,37)$.

Therefore, since JQ1 is a BRD4 inhibitor and BRD4 is positively expressed in OSCC, the regulation of JQ1 of the expression of BRD4 should be elucidated to better understand the antitumor mechanisms of JQ1. Intriguingly, we found that JQ1 repressed expression of BRD4 in the Cal27 cells.

Decades of biological research have identified a central role for C-Myc in the pathophysiology of cancer (38). Abnormal expression of C-Myc is observed in a range of malignancies including breast, colon and cervical cancer, small cell lung carcinoma, osteosarcomas, glioblastomas and myeloid leukemias (39-41). BET bromodomain inhibition by JQ1 was regarded as a therapeutic strategy by which to target C-Myc (39). The present study found that mRNA and protein expression of C-Myc in Cal27 cells treated with JQ1 at different concentrations was significantly downregulated, suggesting that JQ1 suppresses OSCC progression by repressing C-Myc expression.

Twist is a key member of the EMT-activating transcriptional factors which is closely associated with tumor metastasis. Abnormal activation of Twist has been reported in many types of human tumors (42). A recent study demonstrated that overexpression of Twist is associated with OSCC progression and may enhance OSCC cell invasion (43). In addition, Zheng et al reported that Twist was also identified in two types of OSCC cell lines, SCC-4 and TCA8113 cells, and it enhanced cell invasion (44), which provided new insight into the role of Twist in OSCC progression. Shi et al reported that the Twist-BRD4-Wnt5a axis is critical for tumorigenicity in breast cancer, and disrupting the interaction of BRD4 and Twist using JQ1 suppressed tumorigenesis of this malignant cancer (15). Our results, consistent with the above-mentioned data, revealed that both mRNA and protein expression of Twist was significantly downregulated in the Cal27 cells treated with JQ1 when compared with the control group. These data implied that BRD4 inhibition by JQ1 inhibited Cal27 cell invasion through regulation of Twist expression.

In summary, the inhibition of the growth and invasion of OSCC cells by JQ1 was supported by our in vitro results. The investigation of the effect of JQ1 on OSCC in vivo is currently underway and may be explored in-depth in future studies.

\section{Acknowledgements}

The present study was supported by the Science and Technology Development Program of Shandong Province, (grant no. 2014GGH218038), and the Scholarship of Visiting Scholars of Shandong Provincial Key Laboratory of Oral Tissue Regeneration (grant no. SDKQ201404). The authors would also like to acknowledge the grant support from Shandong Provincial Key Laboratory of Oral Tissue Regeneration.

\section{References}

1. Omar E: Current concepts and future of noninvasive procedures for diagnosing oral squamous cell carcinoma - a systematic review. Head Face Med 11: 6, 2015.

2. Chiang CM: Brd4 engagement from chromatin targeting to transcriptional regulation: Selective contact with acetylated histone H3 and H4. F1000 Biol Rep 1: 98, 2009.

3. Wu X, Liu D, Tao D, Xiang W, Xiao X, Wang M, Wang L, Luo G, Li Y, Zeng F, et al: BRD4 regulates EZH2 transcription through up-regulation of C-MYC and represents a novel therapeutic target in bladder cancer. Mol Cancer Ther 15: 1029-1042, 2016.

4. Delmore JE, Issa GC, Lemieux ME, Rahl PB, Shi J, Jacobs HM, Kastritis E, Gilpatrick T, Paranal RM, Qi J, et al: BET bromodomain inhibition as a therapeutic strategy to target c-Myc. Cell 146: 904-917, 2011.

5. Liao YF, Wu YB, Long X, Zhu SQ, Jin C, Xu JJ and Ding JY: High level of BRD4 promotes non-small cell lung cancer progression. Oncotarget 7: 9491-9500, 2016.

6. Wedeh G, Cerny-Reiterer S, Eisenwort G, Herrmann H, Blatt K, Hadzijusufovic E, Sadovnik I, Müllauer L, Schwaab J, Hoffmann T, et al: Identification of bromodomain-containing protein- 4 as a novel marker and epigenetic target in mast cell leukemia. Leukemia 29: 2230-2237, 2015.

7. Li GQ, Guo WZ, Zhang Y, Seng JJ, Zhang HP, Ma XX, Zhang G, Li J, Yan B, Tang HW, et al: Suppression of BRD4 inhibits human hepatocellular carcinoma by repressing MYC and enhancing BIM expression. Oncotarget 7: 2462-2474, 2016.

8. Zuber J, Shi J, Wang E, Rappaport AR, Herrmann H, Sison EA, Magoon D, Qi J, Blatt K, Wunderlich M, et al: RNAi screen identifies Brd4 as a therapeutic target in acute myeloid leukaemia. Nature 478: 524-528, 2011.

9. Shi J, Cao J and Zhou BP: Twist-BRD4 complex: Potential drug target for basal-like breast cancer. Curr Pharm Des 21: 1256-1261, 2015.

10. Wu T and Donohoe ME: The converging roles of BRD4 and gene transcription in pluripotency and oncogenesis. RNA Dis 2: pii: e894, 2015.

11. Leptin M: twist and snail as positive and negative regulators during Drosophila mesoderm development. Genes Dev 5: 1568-1576, 1991.

12. Maestro R, Dei Tos AP, Hamamori Y, Krasnokutsky S, Sartorelli V, Kedes L, Doglioni C, Beach DH and Hannon GJ: twist is a potential oncogene that inhibits apoptosis. Genes Dev 13: 2207-2217, 1999.

13. Li QQ, Xu JD, Wang WJ, Cao XX, Chen Q, Tang F, Chen ZQ, Liu XP and Xu ZD: Twist1-mediated adriamycin-induced epithelial-mesenchymal transition relates to multidrug resistance and invasive potential in breast cancer cells. Clin Cancer Res 15: 2657-2665, 2009.

14. Cheng GZ, Chan J, Wang Q, Zhang W, Sun CD and Wang LH: Twist transcriptionally up-regulates AKT2 in breast cancer cells leading to increased migration, invasion, and resistance to paclitaxel. Cancer Res 67: 1979-1987, 2007.

15. Shi J, Wang Y, Zeng L, Wu Y, Deng J, Zhang Q, Lin Y, Li J, Kang T, Tao M, et al: Disrupting the interaction of BRD4 with diacetylated Twist suppresses tumorigenesis in basal-like breast cancer. Cancer Cell 25: 210-225, 2014

16. Wahlström T and Arsenian Henriksson M: Impact of MYC in regulation of tumor cell metabolism. Biochim Biophys Acta 1849: 563-569, 2015.

17. Dang CV: $M Y C$ on the path to cancer. Cell 149: 22-35, 2012.

18. Vita M and Henriksson M: The Myc oncoprotein as a therapeutic target for human cancer. Semin Cancer Biol 16: 318-330, 2006.

19. Nesbit CE, Tersak JM and Prochownik EV: $M Y C$ oncogenes and human neoplastic disease. Oncogene 18: 3004-3016, 1999.

20. Lüscher B and Vervoorts J: Regulation of gene transcription by the oncoprotein MYC. Gene 494: 145-160, 2012.

21. Delgado MD and León J: Myc roles in hematopoiesis and leukemia. Genes Cancer 1: 605-616, 2010.

22. Rahl PB, Lin CY, Seila AC, Flynn RA, McCuine S, Burge CB, Sharp PA and Young RA: c-Myc regulates transcriptional pause release. Cell 141: 432-445, 2010.

23. Filippakopoulos P, Qi J, Picaud S, Shen Y, Smith WB, Fedorov O, Morse EM, Keates T, Hickman TT, Felletar I, et al: Selective inhibition of BET bromodomains. Nature 468: 1067-1073, 2010. 
24. Shimamura T, Chen Z, Soucheray M, Carretero J, Kikuchi E, Tchaicha JH, Gao Y, Cheng KA, Cohoon TJ, Qi J, et al: Efficacy of BET bromodomain inhibition in Kras-mutant non-small cell lung cancer. Clin Cancer Res 19: 6183-6192, 2013.

25. Lenhart R, Kirov S, Desilva H, Cao J, Lei M, Johnston K, Peterson R, Schweizer L, Purandare A, Ross-Macdonald P, et al: Sensitivity of small cell lung cancer to BET inhibition is mediated by regulation of $A S C L 1$ gene expression. Mol Cancer Ther 14: 2167-2174, 2015

26. Zhang L, Tong Y, Zhang X, Pan M and Chen S: Arsenic sulfide combined with JQ1, chemotherapy agents, or celecoxib inhibit gastric and colon cancer cell growth. Drug Des Devel Ther 9: 5851-5862, 2015.

27. Henssen A, Thor T, Odersky A, Heukamp L, El-Hindy N, Beckers A, Speleman F, Althoff K, Schäfers S, Schramm A, et al: BET bromodomain protein inhibition is a therapeutic option for medulloblastoma. Oncotarget 4: 2080-2095, 2013.

28. Loosveld M, Castellano R, Gon S, Goubard A, Crouzet T, Pouyet L, Prebet T, Vey N, Nadel B, Collette Y, et al: Therapeutic targeting of c-Myc in T-cell acute lymphoblastic leukemia, T-ALL. Oncotarget 5: 3168-3172, 2014.

29. Georgy SR, Cangkrama M, Srivastava S, Partridge D, Auden A, Dworkin S, McLean CA, Jane SM and Darido C: Identification of a novel proto-oncogenic network in head and neck squamous cell carcinoma. J Natl Cancer Inst 107: pii: djv152, 2015.

30. Yu J, Xie F, Bao X, Chen W and Xu Q: miR-300 inhibits epithelial to mesenchymal transition and metastasis by targeting Twist in human epithelial cancer. Mol Cancer 13: 121, 2014.

31. Wang YH, Sui XM, Sui YN, Zhu QW, Yan K, Wang LS, Wang F and Zhou JH: BRD4 induces cell migration and invasion in HCC cells through MMP-2 and MMP-9 activation mediated by the Sonic hedgehog signaling pathway. Oncol Lett 10: 2227-2232, 2015.

32. Ambrosini G, Sawle AD, Musi E and Schwartz GK: BRD4-targeted therapy induces Myc-independent cytotoxicity in Gnaq/11-mutatant uveal melanoma cells. Oncotarget 6: 33397-33409, 2015.

33. Wang YH, Sui YN, Yan K, Wang LS, Wang F and Zhou JH BRD4 promotes pancreatic ductal adenocarcinoma cell proliferation and enhances gemcitabine resistance. Oncol Rep 33: $1699-1706,2015$
34. Zhang Z, Ma P, Jing Y, Yan Y, Cai MC, Zhang M, Zhang S, Peng H, Ji ZL, Di W, et al: BET bromodomain inhibition as a therapeutic strategy in ovarian cancer by downregulating FoxM1. Theranostics 6: 219-230, 2016.

35. Gao X, Wu X, Zhang X, Hua W, Zhang Y, Maimaiti Y, Gao Z and Zhang Y: Inhibition of BRD4 suppresses tumor growth and enhances iodine uptake in thyroid cancer. Biochem Biophys Res Commun 469: 679-685, 2016.

36. Lochrin SE, Price DK and Figg WD: BET bromodomain inhibitors - a novel epigenetic approach in castration-resistant prostate cancer. Cancer Biol Ther 15: 1583-1585, 2014.

37. Baker EK, Taylor S, Gupte A, Sharp PP, Walia M, Walsh NC, Zannettino AC, Chalk AM, Burns CJ and Walkley CR: BET inhibitors induce apoptosis through a MYC independent mechanism and synergise with CDK inhibitors to kill osteosarcoma cells. Sci Rep 5: 10120, 2015.

38. McKeown MR and Bradner JE: Therapeutic strategies to inhibit MYC. Cold Spring Harb Perspect Med 4: 4, 2014.

39. Kandela I, Jin HY and Owen K; Reproducibility Project: Cancer Biology: Registered report: BET bromodomain inhibition as a therapeutic strategy to target c-Myc. Elife 4: e07072, 2015.

40. Conacci-Sorrell M, McFerrin L and Eisenman RN: An overview of MYC and its interactome. Cold Spring Harb Perspect Med 4: a014357, 2014.

41. Meyer N and Penn LZ: Reflecting on 25 years with MYC. Nat Rev Cancer 8: 976-990, 2008.

42. Entz-Werlé N, Stoetzel C, Berard-Marec P, Kalifa C, Brugiere L, Pacquement H, Schmitt C, Tabone MD, Gentet JC, Quillet R, et al: Frequent genomic abnormalities at TWIST in human pediatric osteosarcomas. Int J Cancer 117: 349-355, 2005.

43. da Silva SD, Alaoui-Jamali MA, Soares FA, Carraro DM, Brentani HP, Hier M, Rogatto SR and Kowalski LP: TWIST1 is a molecular marker for a poor prognosis in oral cancer and represents a potential therapeutic target. Cancer 120: 352-362, 2014.

44. Zheng L, Li N, Guo F, Jian XC, Jiang CH, Yin P, Min AJ and Huang L: Twist-related protein 1 enhances oral tongue squamous cell carcinoma cell invasion through $\beta$-catenin signaling. Mol Med Rep 11: 2255-2261, 2015. 